\title{
No man is an island: disentangling multilevel effects in health services research
}

\author{
Michelle Ko, Andrew B Bindman
}

UCSF-Institute for Health Policy Studies, San Francisco, California, USA

\section{Correspondence to} Dr Michelle Ko, UCSF-Institute for Health Policy Studies, 3333 California Street, Suite 265, San Francisco, CA 94118, USA; Michelle.Ko@ucsf.edu

Received 14 October 2013 Revised 28 October 2013 Accepted 28 October 2013 Published Online First 8 November 2013

\section{SLinked}

- http://dx.doi.org/10.1136/ bmjqs-2012-001715

To cite: Ko M, Bindman $A B$. BMJ Qual Saf 2014;23:

177-179.
An extensive literature has established the impact of socioeconomic status on health outcomes. ${ }^{1}$ Across a wide range of conditions, poorer individuals face barriers in access to healthcare and suffer worse outcomes of that care. However, individuals do not exist in a vacuum; experiences and behaviours are shaped by the contexts in which people live, work and seek healthcare. $^{2}$ Financially disadvantaged patients may have worse outcomes as a result of riskier health behaviours, a higher burden of chronic disease, lower levels of education or other individual characteristics. At the same time, aspects of context such as the quality of the healthcare system can further compound these disadvantages. Poorer patients may receive care from lower quality providers or at overburdened clinics with limited care coordination. Thus, we do not know if poor patients experience lower health status primarily because of individual disadvantages and risks, or if contextual factors also play a large role in adverse outcomes.

In this issue of the journal, Lofqvist et $a l^{3}$ try to disentangle the potential explanations for the worse outcomes experienced by financially disadvantaged patients. The specific aspect of healthcare they explore is avoidable hospitalisations. For common chronic illnesses such as asthma, chronic obstructive pulmonary disease, diabetes, hypertension and heart failure, effective ambulatory care should reduce the frequency of hospitalisation. ${ }^{4}$ Using income and hospitalisation data from 43 city districts and municipalities in Stockholm, Sweden, Lofquist et $\mathrm{al}^{3}$ found that residence in the lowest income areas was associated with 29\% higher odds of avoidable hospitalisation for these and other ambulatory care sensitive conditions. They then examined the extent to which this finding is explained by individual-level versus arealevel characteristics.

The authors proposed that low-income patients may have an increased risk of avoidable hospitalisation via a number of pathways including lower baseline health, limited health literacy and poor communication with providers on appropriate care management. The authors also consider that poor individuals tend to reside in poor areas, and the attributes of these areas may contribute to avoidable hospitalisations. They report that, despite a national policy in Sweden to ensure equitable access to healthcare, lowincome areas continue to struggle to recruit high quality providers. Residents are thus disadvantaged by a characteristic of their context, the lower quality of available primary care, and consequently experience a higher rate of avoidable hospitalisations. After adjusting for individual factors, the effect of living in a low-income area remained significant, but reduced to just $5 \%$ higher odds of avoidable hospitalisations. Lofqvist and colleagues conclude that, in Sweden, income-related disparities in avoidable hospitalisation are primarily attributable to individual rather than contextual factors.

\section{CHALLENGES IN CONDUCTING MULTILEVEL HEALTH SERVICES RESEARCH}

This study highlights the challenges in disentangling the effects of individual-level versus contextual-level characteristics in health services research, particularly when most investigations are limited to observational data. First, it is often unclear what geographical unit should be used to measure contextual-level factors. In many cases what is selected is not what is ideal, but rather what is available. For example, Lofqvist $e t a^{3}$ use the municipality or city 
district median income as a measure of area-level socioeconomic status but, as they describe, these areas vary in size from 10000 to 900000 residents. This broad range of variation would bias estimates towards observing no contextual effect. Within the largest districts multiple communities probably exist, each characterised by their own socioeconomic conditions and set of healthcare providers. This complication highlights how it is often difficult to derive meaning from the area being measured-whether this represents a community, a healthcare service area or a policy planning area. Others have grappled with this issue and found that the findings vary by the choice of area-level unit. ${ }^{5}$ The lack of a common, reliable and valid method for measuring the concept of a community undermines our capacity to determine its contribution to healthcare outcomes.

A second research challenge lies in selecting an analytical model that can support inferences about individuallevel factors, contextual factors or both. In their analyses, Lofquist et $a l^{3}$ performed logistic regression models that included both individual- and area-level factors as covariates. Their approach improved over studies that only used individual or contextual measures, but their analytical method limited the extent to which inferences may be drawn about what constitutes a 'contextual' effect. Multilevel analyses should at a minimum account for non-independence-where people live does not occur by chance and is usually highly correlated with individual income. For example, public housing projects will cluster individuals into impoverished neighbourhoods. Failure to account for clustering can lead to the conclusion that contextual effects are present when the observed effect arises because similar individuals tend to live near each other.

\section{CHOOSING AN ANALYTICAL APPROACH}

When sample size permits, hierarchical models offer advantages over models that simply account for clustering. In hierarchical models, regressions are nested to reflect the way the data are nested-that is, people within areas, patients within hospitals, and so on. This modelling approach can be used to separate individual and contextual effects more clearly and to estimate the relative contributions of each. Hierarchical models can be particularly useful for exploring whether the effect of an area-level variable varies depending on the individual in question. In other words, the question becomes not only whether context matters but for whom it matters most.

Evaluation of natural experiments such as social policies implemented at a point of time is another analytical strategy that can strengthen the validity of inferences drawn from observational data. This approach has yielded some surprising results and challenged our understanding of how individual and contextual factors interact. A few groups have studied housing relocations as natural experiments in the USA. Some have found that, after moving to higher-income settings, low-income individuals experience better health outcomes, ${ }^{6}$ whereas others have not. ${ }^{7}$ Ironically, relocating low-income individuals to a higher income community may place them at greater risk of poor health. Traditional safety net providers are no longer available and the resources of the more affluent community, while proximal, are not necessarily accessible. Investigators found that approximately half of individuals who were relocated from public housing programmes in Atlanta, Georgia experienced declines in spatial access to safety net primary care. ${ }^{8}$ Further research may find that the poor derive fewer benefits from residence in a higher-income community than expected-not because context does not matter but because it does so in complex ways that have yet to be fully understood.

Two conceptual frameworks, the Andersen behavioural model $^{2}$ of health services utilisation and the Khan and Bhardwaj socioecological framework, ${ }^{9}$ describe theoretical pathways that link individuals to healthcare providers, systems and communities. Unfortunately, these types of conceptual frameworks are still largely underutilised in health services research for studying contextual effects. Lofqvist et al propose that poorer communities have lower quality providers. However, the healthcare delivery system is only one of many possible reasons why low-income communities have higher rates of avoidable hospitalisations. For example, poorer neighbourhoods also tend to have lower quality education, higher crime and lower environmental safety, all of which could also contribute to worse health outcomes. ${ }^{1}$ For lowincome individuals, improving the geographical availability of high quality primary care may not overcome other community or individual barriers. Ultimately, the choice of analytical approach should lie in specifying the potential relationship between individual and contextual factors and healthcare outcomes.

\section{WHERE DO WE GO FROM HERE? IMPLICATIONS FOR POLICY AND PRACTICE}

Exploring the relative contributions of individual versus contextual effects is not merely an academic exercise: important policy decisions depend on knowing the relative contributions of these two categories of effects. Policies that target individuals range from universal healthcare coverage to education initiatives focused on healthy behaviours and effective selfmanagement strategies. Policies that target healthcare systems may include financial incentives and quality improvement efforts for providers who locate their practices in underserved areas. Other policies do not target the healthcare system but may still improve individual health by targeting environmental hazards and access to healthy food choices. ${ }^{10}$ One take-away message from the work of Lofquist et al is that attending to either individual or contextual factors in isolation is not enough. Sweden has a universal health 
insurance coverage system but it still has variability in its avoidable hospitalisation rates across communities.

People in the USA undoubtedly face significant contextual barriers to care, but they have been somewhat masked by the more glaring individual level barrierthe high rate of uninsurance. The Affordable Care Act centres on providing a greater percentage of Americans with health insurance, with far less support dedicated to improving shortages of healthcare providers in underserved rural and inner city areas. Unless the necessary contextual factors are also in place, we may find that coverage expansion alone is not enough to improve access to care and reduce avoidable hospitalisations. ${ }^{11}$

The work by Lofquist et al does not provide definitive answers regarding the role of individual and contextual factors on health, but it illustrates how health services researchers need to pursue this challenge in order to guide policies to improve access and quality of care.

Contributors Both authors provided substantial contributions to the conception, drafting and revision of the work. Final approval has been granted by both authors, and both authors accept responsibility for the accuracy and integrity of the work. Competing interests None.

Provenance and peer review Not commissioned; externally peer reviewed.

\section{REFERENCES}

1 Braveman PA, Egerter SA, Mockenhaupt RE. Broadening the focus: the need to address the social determinants of health. Am J Prev Med 2011;40(1 Suppl 1):S4-18.
2 Davidson PL, Andersen RM, Wyn R, et al. A framework for evaluating safety-net and other community-level factors on access for low-income populations. Inquiry 2004;41:21-38.

3 Lofqvist T, Burstrom B, Walander A, et al. Inequalities in avoidable hospitalization by area income and the role of individual characteristics: a population-based register study in Stockholm County, Sweden. BMJ Qual Saf 2014;23:206-14.

4 Bindman $\mathrm{AB}$, Grumbach K, Osmond D, et al. Preventable hospitalizations and access to health care. JAMA 1995;274:305-11.

5 Mobley LR, Kuo TM, Andrews L. How sensitive are multilevel regression findings to defined area of context? A case study of mammography use in California. Med Care Res Rev 2008;65:315-37.

6 Ludwig J, Sanbonmatsu L, Gennetian L, et al. Neighborhoods, obesity, and diabetes-a randomized social experiment. $\mathrm{N} \mathrm{Engl}$ J Med 2011;365:1509-19.

7 Keene DE, Geronimus AT. "Weathering" HOPE VI: the importance of evaluating the population health impact of public housing demolition and displacement. J Urban Health 2011;88:417-35.

8 Cooper HL, Wodarski S, Cummings J, et al. Public housing relocations in Atlanta, Georgia, and declines in spatial access to safety net primary care. Health Place 2012;18:1255-60.

9 Khan AA, Bhardwaj SM. Access to health care. A conceptual framework and its relevance to health care planning. Eval Health Prof 1994;17:60-76.

10 Braunstein S, Lavizzo-Mourey R. How the health and community development sectors are combining forces to improve health and well-being. Health Aff (Millwood) 2011;30:2042-51.

11 Baicker K, Taubman SL, Allen HL, et al. The Oregon experiment-effects of Medicaid on clinical outcomes. N Engl J Med 2013;368:1713-22. 